\title{
Preparing potential teachers for the transition from employment to teacher training: A evaluative case study of a Maths Enhancement Course
}

\author{
*Steve May, B.Eng, MSc, Cert Ed, Senior Researcher, Kingston University \\ Jane Gay, BA (Hons), PG.Cert, Senior Lecturer, Kingston University \\ Nigel Atkins, PhD, BSc, Principal Lecturer, Kingston University \\ Diane Marks-Maran, MA, BSC, RN, Visiting Professor, Kingston University and St George's \\ University of London
}

${ }^{*}$ Corresponding author

\section{Abstract}

In response to a UK government drive to improve maths teaching in schools, the South West London Maths Enhancement Course (MEC) has been set up though collaboration between three Higher Education institutions (HEls) to provide an efficient route for non maths graduates in employment to upgrade their subject knowledge and give a smooth transition into teacher training (PGCE).

An evaluation of the scheme, measured against Teacher Development Agency (TDA) objectives and success criteria agreed by university staff, involved thematic analysis of focus group discussions and interviews with students and staff during both the MEC and PGCE courses. This has revealed a high level of satisfaction and success related to a number of underlying issues, particularly around student recruitment, curriculum design, peer support and staff collaboration. The model offers an example of practice transferable to a range of programmes aimed at supporting students in the transition between levels and institutions.

\section{Introduction}

The importance of the UK government strategy to raise educational standards, reflected in its aims of "every primary school offering high standards in the basics" and "every secondary school offering excellence in teaching" (DfES 2004, p4), is brought into sharp focus by a conclusion in the foreword to the Leitch report: 
"The prize for our country [with increased skills] will be enormous- higher productivity, the creation of wealth and social justice [alternatively] without increased skills we would condemn ourselves to a lingering decline in competitiveness, diminished economic growth and a bleaker future for all" (Leitch 2006, p1)

The need for the development of numeracy and mathematics skills in particular was highlighted by a government commissioned report into the supply of graduates with science, technology, engineering and mathematics qualifications (Roberts 2002); which indicated that there was a downward trend in the numbers of students studying mathematics (as well as engineering and the physical sciences) despite the fact that graduates within these strongly numerical skill areas are in increasing demand, and concluded that this is resulting in a skills shortage. The subsequent Smith inquiry into post 14 mathematics education found there to be a "failure of the current curriculum, assessment and qualifications framework in England, Wales and Northern Ireland to meet the needs of many learners and to satisfy the requirements and expectations of employers and higher education institutions" (Smith 2004, p3).

The training and development agency (TDA) was set up by the erstwhile Department for Education and Skills (DfES) with a critical role in the development of skills through contributing to the development of an effective and secure workforce (TDA 2007a). One initiative instigated to achieve this is the setting up of subject enhancement courses to prepare graduates lacking subject specific skills for teacher training programmes in the shortage areas of maths, chemistry, physics, French and German. By 2007 there were 20 maths enhancement courses (MECs). 
The structure, components and assessment regime of the original MEC programme were developed by a working group that included mathematics academics and Initial Teacher Training (ITT) tutors and the course piloted at two institutions over two years (TDA 2003). The evaluation of this (TDA 2007b) highlighted the benefits of a close knit team of staff and recommended a greater emphasis on developing a deep understanding of mathematics in students. These, and other recommendations, were taken account of by each of the twenty subsequent providers leading to the development of distinctive models for individual programmes that were firmly rooted in the philosophy and principles set out in the original specification (TDA 2003). The South West London MEC partnership, influenced by the evident success of the pilot course and hence the value of using it as a starting point for future development, opted to purchase the original model. The partnership was based on the well-established South West London Teacher Education Consortium (SWELTEC) and designed to utilise the various institutional staffing strengths and to meet the regional needs for mathematics enhancement through referral from ITT providers. Its first student cohort commenced in January 2006.

The recruitment process is considered by the staff team to be a key aspect of the programme's success. Potential students are required to secure a PGCE place before selection to the MEC can proceed; the lecturer responsible for recruitment then carries out individual interviews drawing on data provided in a detailed application form.

Consideration of applicants' personalities and potential as teachers is given a high priority with those selected having demonstrated qualities and characteristics likely to induce positive responses from pupils. Selection criteria were formulated in recognition that teaching is a collaborative skill and include a requirement of evidence of applicants' openness to learning and willingness to respond constructively to criticism. 
The structure of the MEC reflects its objective of intensive subject delivery; it runs for 6 months from January to July, essentially with two terms containing four study units each. The first is designed to ease students into the course through providing a body of material which underpins the ' $A$ ' level or equivalent mathematics that they require to enter the programme. This revision is seen as essential both for their subject knowledge and to build confidence; many have made significant lifestyle changes for themselves and their families to embark on the MEC and, as such, are vulnerable to self doubt, which this approach aims to minimise. The first term also includes course induction sessions, which although mathematical in nature are chosen to be fun and to foster early student interaction. Throughout their study at the university students attend four days each week, with directed study periods scheduled to coincide with half term and Easter school holidays. There is a week of school based observation giving the opportunity for involvement in issues around the practical aspects of teaching.

The consortium of MEC providers consists of both Education and Mathematics academics, one beneficial outcome of this is that the students are exposed to a variety of teaching styles. Relevant educational software is integrated throughout, whilst small group and plenary discussions figure significantly in the paradigm to help realise the TDA objective of "deep understanding" (TDA 2003, p2). The students are continually reminded that this important outcome must not be compromised by developing a formulaic approach to passing assessments, which themselves take the form of individual and small group presentations, coursework, portfolios and time-limited tests.

The perceived success and novel aspects of the MEC, particularly in terms of the method of student recruitment, curriculum design and cross institutional collaboration, led 
the course team at Kingston University to commission its Academic Development Centre to carry out an evaluation of the course with the aim of measuring its performance against the TDA and University objectives, and uncovering underlying issues and practices, in particular those which may, to a lesser or greater extent, be transferable to other programme areas.

\section{Method}

A case study methodology was developed through consultation with the course team and building on the TDA objective of raising the number of candidates eligible to teach mathematics by "enhancing the knowledge and understanding [of mathematics] in potential ITT (Initial Teacher Training) trainees" (TDA 2003). The specific success criteria identified were:

1. Students will gain the subject knowledge needed to commence a Post Graduate Certificate programme and to teach mathematics.

2. Students will improve skills that are important to teaching, such as confidence and communication.

3. Students' expectations of the course will be realised.

4. Students will gain insights into mathematics teaching through working in groups

Multiple methods of data collection were employed in line with descriptive case study design (Yin 1994; Tellis 1997). Student entry qualification, assessment results, and progression rates onto the PGCE were initially gathered. To further assist analysis of the 
underlying factors further qualitative data were collected as summarised in Table 1. MEC students attended a focus group at the end of the programme in July 2006 at which they $(n=10)$ were encouraged to discuss their experience on the course under prompts relating to the success criteria. To encourage reflection in the light of the teacher training experience these were repeated between January and March 2007 with groups at two of the teacher training institutions (TTIs) at which the students had subsequently enrolled. The focus groups were designed in accordance with the methods outlined by Merton, Fiske \& Kendall (1990) to cover the maximum range of relevant topics, provide specific data that could be coded and analysed, explore the participants' feelings through facilitating group interaction, and to take into account the personal contexts of the participants. In addition telephone interviews were conducted with three of the former MEC students at a third TTI and a face to face interview with one from a fourth. A staff perspective was gathered via interviews with two MEC course directors, one of whom also taught on the ITT course.

Table 1. Qualitative data collected from MEC participants

\begin{tabular}{l|l|l|l} 
& \multicolumn{3}{|c}{ Data collection method } \\
\cline { 2 - 4 } Participants & Focus group & $\begin{array}{l}\text { Individual interview } \\
\text { (Telephone) }\end{array}$ & $\begin{array}{l}\text { Individual interview } \\
\text { (Face to face) }\end{array}$ \\
\hline $\begin{array}{l}\text { MEC students on MEC } \\
\text { course } \\
\text { (July 2006) }\end{array}$ & Kingston $(n=10)$ & & \\
$\begin{array}{l}\text { MEC students on } \\
\text { PGCE } \\
\text { (Jan - March 2007) }\end{array}$ & $\begin{array}{l}\text { Roehampton }(n=4) \\
\text { St. Mary's }(n=4)\end{array}$ & Brunel $(n=3)$ & Kingston $(n=1)$ \\
$\begin{array}{l}\text { Course director } \\
\text { (Jan - March 2007) }\end{array}$ & & & \\
& & & St. Mary's $(n=1)$ \\
\end{tabular}

The sessions were audio recorded and transcribed after which data analysis was undertaken using the five stage Framework Method for qualitative data analysis (Ritchie \& Spencer 1993) as shown in Table 2 
Table 2. Analysis of the qualitative data (from Ritchie \& Spencer 1993)

\section{Familiarisation}

The transcripts of audio recordings and the notes taken were read and discussed by the research team.

\section{Identifying a thematic framework}

All key issues, concepts and recurring statements were grouped into themes identified from within the data and listed giving a detailed numerical index

\section{Indexing}

All passages within the text were annotated with the numerical index

\section{Charting}

The coded text was tabulated according to the identified themes

\section{Mapping and interpretation}

The themes were analysed for association between one another and mapped against the objectives and success criteria (see table 3).

This yielded four major themes which are outlined in the next section and analysed in the context of the initial success criteria in the discussion.

\section{Findings}

Initial discussions with staff concluded that age, the type of subjects previously studied at degree level and the level of maths attainment prior to starting the degree were the most likely pre-entry variables to be related to student attainment on the MEC. Table 3 shows the initial qualifications and age on entry of each student in the cohort ranked by their overall mean score at the end of the course. This is the mean of the module scores where each assessment was graded on a scale between 0 (fail) and 3 (Exceptional performance). It is apparent that the type of degree taken and age of students were not associated with attainment but, where students had taken maths A level, those with higher grades tended to outperform their peers. 
Table 3. MEC Student Attainment and background

$\begin{array}{rllr}\begin{array}{r}\text { Overall } \\ \text { attainment }\end{array} & \text { Maths } & & \begin{array}{r}\text { Age } \\ \text { A-level }\end{array} \\ \text { Score } & \text { grade } & \text { Name of the degree achieved prior to starting the MEC } \\ \text { Entry } \\ 2.59 & \text { B } & \text { European Management Science with German } & 29 \\ 2.55 & \text { B } & \text { MSc Cognitive Science } & 32 \\ 2.24 & \text { B } & \text { BA Hons Leisure Management } & 29 \\ 2.21 & \text { B } & \text { BSC(Hons) Economics } & 22 \\ 2.20 & \text { B } & \text { BA (Hons) Psychology } & 28 \\ 2.15 & & \text { BA Law and Marketing } & 30 \\ 2.14 & \text { C } & \text { Economics and Business Economics } & 42 \\ 2.04 & \text { B } & \text { BA Management and Business Administration } & 24 \\ 1.98 & & \text { Information Management \& Information Systems } & 30 \\ 1.94 & \text { E } & \text { MA Economics } & 27 \\ 1.84 & & \text { BSc Agricultural Economics } & 33 \\ 1.80 & & \text { BA English Literature } & 22 \\ 1.79 & & \text { BA Business Management and Finance } & 22 \\ 1.78 & & \text { BSc Chemical Engineering } & 34 \\ 1.70 & \text { C } & \text { BSc (Hons) Business Economics } & 22 \\ 1.69 & \text { D } & \text { LLB Law } & 22 \\ 1.68 & & \text { BSc(Hons) Multimedia Communications } & 23 \\ 1.68 & \text { C } & \text { BSc Economics; MSc Information Systems Design - } & 29 \\ 1.59 & \text { E } & \text { BSc Computing } & 29 \\ 1.52 & & \text { Business Management } & 22 \\ 1.43 & & \text { BSc Economics, Finance \& Management } & 22 \\ 1.40 & & \text { BSc in Accounting and computing } & 23 \\ 1.36 & & \text { BA (Hons) International Marketing } & 23 \\ 1.28 & & \text { BA Economics of Business } & 33 \\ 1.21 & & \text { BSc Forensic Science } & 25 \\ 1.19 & & \text { BA LLB Hons in Law } & \text { BA (Hons) Economics } \\ 1.18 & & & \end{array}$

The qualitative analysis of the data from the students and course directors in line with the framework outlined in Table 2 resulted in the emergence of 4 major themes and 32 sub-themes. Table 4 shows the themes that recurred at least 5 times and were associated with the success criteria to illustrate the main issues uncovered 
Table 4. Mapping themes from focus groups and interviews with the success criteria

Themes (number of passages identified in the transcripts)

Main Themes: $\begin{array}{llll}\text { Value of MEC } & \text { Group cohesion } & \text { Meeting expectations }\end{array}$ MEC Success Criteria for PGCE students

Students will gain the subject knowledge needed to commence a Post Graduate Certificate Success in terms of

programme and to teach mathematics.

proceeding to PGCE (7)

Students will improve skills that are important to Value of MEC in terms of

teaching, such as confidence and

experiencing teaching

methods and resources

(14)

Networking in schools

communication.

Collaborative learning (5)

maths-related

skills/knowledge (22)

life skills (29)

potential as teachers (5)

Confidence gained through MEC (14)

Critical self-awareness developed through MEC (7)

\begin{tabular}{|c|c|c|}
\hline $\begin{array}{l}\text { Students' expectations of the course will be } \\
\text { realised. }\end{array}$ & MEC was valuable (21) & $\begin{array}{l}\text { Expected difficulty v. } \\
\text { actual difficulty (12) } \\
\text { Personal learning of } \\
\text { maths v. pedagogic } \\
\text { learning (11) }\end{array}$ \\
\hline $\begin{array}{l}\text { Students will gain insights into mathematics } \\
\text { teaching. }\end{array}$ & $\begin{array}{l}\text { Valued the quality of } \\
\text { teaching in MEC (8) }\end{array}$ & $\begin{array}{l}\text { Personal learning of } \\
\text { maths } v \text {. pedagogic } \\
\text { learning (11) }\end{array}$ \\
\hline
\end{tabular}




\section{Theme 1 -Value of the MEC}

"I am glad to have done MEC...I met people and got to the nitty-gritty of maths" (PGCE focus group)

A high proportion of statements made by respondents $(28 \%)$ indicated that the MEC was valuable, with none to the contrary. Alongside this, a number areas where MEC could be improved were identified including the way it is marketed, with some students reporting "finding out about MEC by accident". There were also organisational issues that students felt could be improved, in particular: timetabling their presentations more evenly across the course and creating a better balance between term 1 and term 2. A major sub-theme that emerged was the value of the MEC in terms of the enabling students to experience a range of teaching methods and gain useful teaching resources.

"...so I think once they get on the PGCE they're much more responsive to the non-text book approaches. And that's a real tool that I think makes them better teachers" (course director)

"we didn't just look at methods and kind of text book ways of looking at it. There was a more investigative approach that was taken on the MEC." (PGCE student interview)

“it's funny but software was really, really helpful. ... I didn't know about how to multiply things in the grid method and things like that ....and new things 
that have come up since I have been in, I went to school. So it was

extremely useful I must say". (PGCE student interview)

\section{Theme 2 -Bonding/group cohesiveness}

"We are a close sort of bunch. The four of us (who had done the MEC together and now are on the PGCE) get on well...We find it naturally quite easy to get into a group and start discussing something." (MEC student)

Statements supporting the sub-themes of peer group support, group working, collaborative working and networking skills, perceived to be a direct result of the MEC, were fairly evenly distributed. The data suggests that this same level of bonding and cohesiveness was less evidence in the non-MEC PGCE students.

"Our motto (on the MEC) is 'share your learning by teaching others.' They (MEC students) support each other...they share successes as well as, 'I'm having a bad day.' They are much more open with each other (than the other PGCE students)." (PGCE teacher)

"We still communicate with each other (after the MEC). We have actually set up a Yahoo thing where we communicate with each other...we get ideas off each other...we have even had a reunion." (MEC student) 


\section{Theme 3 -Expectations of the MEC versus actual experiences}

"I got warned before I started that the PGCE would be the worst year of my life! And it is quite intense, but because the MEC was so intense I haven't found it so much of a shock, whereas I think some of the others (the non MEC PGCE students) have found it quite a shock. I am so much more prepared for the PGCE because of MEC." (MEC student)

The third broad theme concerned expectations of MEC that students had prior to starting and the extent to which their experience met these expectations. Of the five subthemes two emerged as dominant - expected difficulty of MEC versus actual difficulty and personal learning of maths versus pedagogic learning.

"They (The MEC students) know hat the MEC is about pedagogic learning rather than personal learning of maths. Its not about passing exams so much as it is about learning how to explain it to someone else" (Course director)

\section{Theme 4 -Advantages of the MEC for PGCE students}

"I definitely think that the people who did the MEC were much more prepared for the PGCE. When we started...everyone said, .'Wow - that would have been really good for me to do as well.' (MEC student)

A high number of statements from students and staff emphasised the perceived differences, particularly in terms of better developed study skills and maths knowledge, confidence, critical self-awareness and level of perceived preparation, between those who 
had and had not completed the MEC prior to starting the PGCE. These indicated that those who had undertaken the MEC were more advanced than those who had not. Within this theme, the dominant sub-themes were maths-related knowledge and skills, level of life/study skills and degree of confidence gained as a result of MEC.

“The (non-MEC) PGCE students...they'd done a degree....and were good at what they were doing but when it came to looking at GCSE and the different approaches and methods, they had not thought about it...On the MEC we had already done that." (MEC student)

"Their presentation skills are way ahead of the non-MEC PGCE students." (PGCE teacher)

"Organisationally, they (MEC students) are significantly better. They are used to keeping files and records." (PGCE teacher)

\section{Discussion}

The findings from this case study indicate that realisation of the TDA aim to build an effective teaching workforce that better reflects the diversity of the pupil population is likely to be served by MECs and that the success criteria for the programme defined by the course team have been largely met. The prime objective of the MEC, as stipulated by the TDA, was to give the students the subject knowledge needed to start the teacher training course, it clearly succeed for this cohort with all students successfully progressing onto PGCE programmes. 
The backgrounds of the MEC students varied considerably in terms of age and tertiary education as shown in table 3 but it transpires that it was their performance at maths ' $A$ ' level rather than their age or experience as graduates that was associated with their grade attainment on the MEC, suggesting that while a good ' $A$ ' level in maths need not be a requirement for the course it is a significant attribute where held.

The importance of the MEC, as a stepping stone to teacher training, through supplying the maths subject knowledge necessary, was highly valued by students. Particularly given the intense nature of the course, their working together as a learning community and forming individual bonds were essential parts of their subject learning experience. Other research, including at this institution, strongly indicates that, particularly for diverse groups, developing ways of learning collaboratively may be highly beneficial (see for example Ashwin 2003, May \& Gay 2007). One of the explanations for the success of the MEC is, we believe, related to the seeking of evidence of potential for group working as a selection criteria in the recruitment process. The extensive work being carried out to enhance the student learning experience, particularly through peer assisted learning and helping students to form learning communities (see for example May \& Hodgson 2006, Smith et al 2007), is to some extent validated by the findings from this MEC evaluation.

PGCE staff reported that the subject knowledge of the MEC students prepared them well for the course and students themselves found that they had gained the maths skills necessary for success. While they appreciated that their mathematical ability may not match that of maths graduates entering the course, there was a clear consensus that this was outweighed by their superior confidence, communication and organisational skill developed through the MEC along-side a deeper understanding of the pedagogy. Students, when studying on both the MEC and PGCE courses, placed a high value on the 
development of skills that they could see to be important to their performance as teachers. The MEC staff team, in its development of the curriculum, placed a strong emphasis on modelling a range of teaching techniques and utilising appropriate resources including teaching software and interactive whiteboards. Students felt that the MEC had given them distinct advantages over others on PGCE courses through its curriculum design having particularly helped improve their time management and organisational skills; while working with one another at the University and networking with staff at their placement schools empowered them to build the self awareness and confidence to develop written and oral communication skills. Underhill (1991) highlights the importance of the facilitative role of groups in the development of critical self awareness as a means to facilitate the self education of others, and as Richardson \& Shupe $(2003, \mathrm{p} 5)$ concludes "if teachers make conscious, ongoing efforts to increase their own self-awareness, they will likely enhance their effectiveness and their job satisfaction".

That student expectations of the course should be realised was considered important by the course team particularly to maintain high retention rates since other work at Kingston University (May \& Bousted 2004) and elsewhere (for example Yorke 2000) has highlighted this as a prime reason given by students for withdrawal. Our findings indicate that the students had been led to believe that the PGCE was going to be a very difficult year but had not thought that the MEC would be as intense; what emerged is that the latter was more intensive than they had anticipated and the PGCE year less so. They reported that their expectations of developing teaching skills and learning practical aspects of teaching on the PGCE were not being met, rather, it was described as being a "more theoretically based" course. Conversely, they considered that the MEC was more helpful in developing their teaching skills; this served to emphasise the importance to the staff 
team of smoothing the transition to the PGCE by further preparing students for the reality of what it entails.

The MEC aim of giving students insights into mathematics teaching, while not explicitly specified by the TDA, was felt by the course team to be important for fostering a deep learning through an understanding of pedagogy that would enhance their experience on the PGCE and beyond. The curriculum design sought to achieve this partly through encouraging group activities and discussion in line with the finding by Chin \& Brown (2000, p 109) that "to encourage a deep learning approach, teachers could provide prompts and contextualized scaffolding and encourage students to ask questions, predict, and explain during activities". Participants clearly found the group work and associated development of skills helpful for both MEC and PGCE courses. Insights into teaching thus achieved appear to have evolved from such discussions; their learning from one another helping to raise awareness of the learning process. As Boud, Cohen \& Sampson (1999, p416) suggest learning from peers helps those involved in "learning-how-to-learn".

The recurrence of comments from students around the value they placed on the high quality of the teaching from staff was also linked with their gaining insights into its pedagogy. The use of varied teaching methods, designed to illustrate techniques that could address the needs of a range of possible learning styles in pupils, acted as a stimulus while on the MEC and gave them an advantage over others on PGCE courses. The term "pedagogic knowledge" of maths emerged to describe the difference between understanding maths personally and being able to explain it to others; the data, particularly from the PGCE teacher, indicated that MEC students had greater pedagogic knowledge of maths than other trainee teachers. This, we believe, highlights the advantages of designing a far sighted curriculum that goes beyond preparation of students 
to meet subject related objectives towards focussed preparation for the next stage of their education.

Collaboration between staff from Mathematics and Education departments within an $\mathrm{HEI}$ and with those from the institutions to which the students progress has driven the development of recruitment and curriculum design, in particular relating to peer support, that promote deeper understanding and approaches to learning by students. It is this, we posit, that will prove most effective in providing future teachers with the ability and enthusiasm to raise the mathematical skills of children.

We conclude that the success to date of the South West London MEC stems from its focus on aiming to produce teachers with the potential to raise mathematics skill levels in UK schools. This model is adding to the understanding of admissions, and teaching and learning strategies at Kingston University and offers an example of transferable practice to a range of programmes aimed at supporting students in the transition between levels and institutions. 


\section{References}

Ashwin, P. 2003. Peer facilitation and how it contributes to the development of a more social view of learning. Research in Post-Compulsory Education. 8, no. 1: 5-17.

Boud, D., Cohen, R. \& Sampson, J. 1999. Peer learning and assessment. Assessment \& Evaluation in Higher Education. 24, no. 4: 413-426.

Chin, C. \& Brown, D.E. 2000. Learning in Science: A Comparison of Deep and Surface Approaches. Journal of Research in Science Teaching 37, no. 2: 109-138.

DfES 2004. Department for Education and Skills: Five Year Strategy for Children and Learners Putting people at the heart of public services. London: HMSO.

Leitch, S. 2006. Prosperity for all in the global economy Final Report. Norwich: HMSO.

May, S. \& Bousted, M. 2004. Investigation of student retention through an analysis of the first-year experience of students at Kingston University. Widening Participation and Lifelong Learning 6, no. 2: 42-48.

May, Steve \& Gay, Jane. 2007. Peer Support: Development of peer support initiatives to fit a changing student agenda. Paper presented at First European First Year Experience Conference, April 26-28, University of Teesside, Middlesbrough, UK.

May, S., Hodgson, D. \& Marks-Maran, D. 2005. Feet under the table: students' perceptions of the effectiveness of learning support provided during their first year of study on health and social care programmes. Paper presented at the Society for Research into Higher Education Conference, 13-15 December, University of Edinburgh, UK.

Merton, Robert, K., Fiske, Marjorie, \& Kendall, Patricia. L. 1990. The focused interview. New York: Free Press. 
Richardson, B.G. \& Shupe, M.J. 2003. The Importance of Teacher Self-Awareness in Working With Students With Emotional and Behavioral Disorders. Teaching Exceptional Children 36, no. 2: 8-13.

Ritchie, J. \& Spencer, L. 1993. Qualitative data analysis for applied policy research. In Analysing qualitative data, eds. A. Bryman \& R. Burgess, London: Routledge.

Roberts, G. 2002. SET for success: The review of Sir Gareth Roberts. London: HM Treasury.

Smith, A. 2004. Making Mathematics Count. Norwich: The Stationary Office Limited.

Smith, J., May, S. \& Burke, L. 2007. Peer assisted learning: a case study into the value to student mentors and mentees. Practice and Evidence of the Scholarship of Teaching and Learning in Higher Education (in press).

TDA 2007a. 2007-10 Corporate plan: developing people, improving young lives. London: Training and Development Agency for Schools.

TDA 2007b. Evaluation of the Pre-ITT pilot enhancement courses in mathematics. London: Teacher development agency for schools.

TDA 2003. Spending Review Funding: New Programmes. London: Training and Development Agency for Schools.

Tellis, W. (1997) Introduction to Case Study. The Qualitative Report 3(2). Available: http://www.nova.edu/ssss/QR/QR3-2/tellis1.html

Underhill, A. 1991. The role of groups in developing teacher self-awareness. English Language Teaching Journal 46, no. 1: 71-80. 
Yin, R. 1994. Case study research: Design and methods. Beverly Hills, CA: Sage Publishing.

Yorke, M. 2000. The Quality of the Student Experience: what can institutions learn from data relating to non-completion? Quality in Higher Education 6, no. 1: 61-76. 